\title{
APLICAÇÃO DAS ANÁLISES ESPECTROSCÓPICAS E TERMOGRAVIMÉTRICAS EM FILMES BIODEGRADÁVEIS DE AMIDO DE MILHO INCORPORADOS COM EXTRATO DE PRÓPOLIS-VERDE ${ }^{1}$
}

\author{
Leonardo Silva Santos Lapa ${ }^{2}$ \\ Yago Ribeiro de Oliveira Silva \\ Priscila Ferreira de Sales
}

\begin{abstract}
RESUMO
Foi estudada a síntese de filmes biodegradáveis (método casting) de amido de milho que foram incorporados com extrato de própolis-verde. Com a finalidade de verificar a influência da quantidade em massa de amido de milho, glicerina e extrato de própolis-verde, foi empregado o planejamento fatorial completo. Os materiais sintetizados foram caracterizados por Espectroscopia na região do Infravermelho com Transformada de Fourier (FTIR) e análise termogravimétrica, sendo ainda avaliadas suas propriedades organolépticas relacionadas ao aspecto visual e tátil. É possível inferir que os filmes biodegradáveis produzidos com quantidades intermediárias de amido de milho (quatro gramas) e mais elevadas de glicerina (um grama) podem facilmente ser aplicados como coberturas e proteção de produtos alimentícios, visto que, além dos mesmos serem removidos de maneira adequada da placa de suporte, apresentam características visuais adequadas. Além disso, foi evidenciado, pela análise termogravimétrica, que os mesmos são estáveis na temperatura ambiente e pela análise FTIR foi verificado que, em todas as formulações propostas no planejamento quimiométrico, está presente o extrato de própolis-verde que de, acordo com a literatura, constitui-se de uma mistura complexa de compostos que apresentam atividade antioxidante.
\end{abstract}

Palavras-chave: Análise térmica. Biofilmes. Infravermelho.

\section{APLLICATION OF SPECTROSCOPIC AND THERMOGRAVIMETRIC ANALYSIS IN BIODEGRADABLE FILMS OF CORN STARCH INCORPORATED WITH PROPOLIS-GREEN EXTRACT}

\begin{abstract}
It was studied the biodegradable cornstarch films (casting method) synthesis with green propolis extract incorporated. In order to verify the cornstarch, glycerin and green propolis extract mass amount influence, the full factorial design was applied. The synthesized materials were characterized by

\footnotetext{
${ }^{1}$ Como citar este artigo:

LAPA, L. S. S.; SILVA, Y. R.O.; SALES, P. F. Aplicação das análises espectroscópicas e termogravimétricas em filmes biodegradáveis de amido de milho incorporados com extrato de própolis-verde. ForScience, Formiga,
} v. 8, n. 2, e00712, jul./dez. 2020. DOI: 10.29069/forscience.2020v8n2.e712.

\footnotetext{
${ }^{2}$ Autor para correspondência: Leonardo Silva Santos Lapa, e-mail: leonardo_lapa@yahoo.com.br.
} 
Fourier-transform infrared spectroscopy (FTIR) and thermogravimetric analysis. Their organoleptic related properties to tactile and visual aspects were also evaluated. It is possible to infer that biodegradable films produced with intermediate amounts of cornstarch (four grams) and higher glycerine amounts (one gram) can easily be applied as coatings and protection to food products, since these are properly removed from the support plate and presents suitable visual characteristics. In addition, it was evidenced by the thermogravimetric analysis that the cornstarch biofilms are stable at room temperature. It was verified by the FTIR analysis that the green propolis extract, which according to the literature it constitutes of a complex mixture of antioxidant activity compounds, is present in all chemometric planning proposed formulations.

Keywords: Thermal analysis. Biofilms. Infrared.

\section{INTRODUÇÃO}

A utilização de embalagens provenientes de polímeros de origem petroquímica traz prejuízos devastadores, uma vez que se degradam lentamente por serem resistentes às radiações, ao calor, ao ar, à água e ao ataque imediato de microrganismos (UGALDE et al., 2017).

Neste contexto, várias alternativas têm sido investigadas com o intuito de minimizar o impacto ambiental dos polímeros convencionais. Dentre elas, ressalta-se a utilização de materiais biodegradáveis oriundos de recursos renováveis e com potencial comestível para serem aplicados em embalagens (UGALDE et al., 2017; ARAÚJO et al., 2012).

A elaboração de filmes biodegradáveis envolve a utilização de um agente formador de filme (macromoléculas), solvente (água, metanol, etanol, acetona, entre outros), plastificante (glicerol, sorbitol, etc.), podendo ainda ser incorporados aditivos (ARAÚJO et al., 2012). O método de casting para a produção de filmes biodegradáveis consiste no preparo de uma solução coloidal da macromolécula (solução filmogênica) com a presença ou não de aditivos, sua deposição em um suporte adequado e posterior secagem do solvente (PARZANESE, 2019). A utilização do amido de milho como agente formador se baseia nas propriedades químicas, físicas e funcionais da amilose para formar géis e na sua capacidade para formar filmes. O seu uso tem sido enfatizado na literatura pelo mesmo ser considerado uma matériaprima vegetal, abundantemente encontrada na natureza, custo relativamente baixo e ser uma grande fonte de exploração econômica (MATTA JÚNIOR, 2009).

O plastificante é definido como uma substância incorporada aos filmes biodegradáveis com o intuito de melhorar a sua flexibilidade e funcionalidade, sendo destacado, no presente trabalho, a utilização da glicerina. A mesma pode interagir fortemente com o amido de milho por meio de forças intermoleculares do tipo ligações de hidrogênio (HORN, 2012). 
A própolis consiste em uma mistura de substâncias resinosas que abelhas da espécie Apis mellifera Linnaeus, 1758 coletam de várias plantas e a utilizam para proteção de crias e conservação da alimentação no interior da colmeia. A substância tem diversas aplicações médicas, biológicas (antimicrobiana e a antiinflamatória) descritas na literatura (SALATINO et al., 2005; ARAÚJO et al., 2016), sendo considerada uma das misturas mais heterogêneas encontradas em fontes naturais, sendo identificados e/ou caracterizados mais de 300 constituintes, os quais incluem ácidos graxos e fenólicos, ésteres, ésteres fenólicos, flavonóides, terpenos, esteróides, aldeídos, ácidos aromáticos, sesquiterpenos, naftaleno, vitaminas (B1, B2, B6, C, E) e minerais (manganês, ferro, cálcio e alumínio) (ARAÚJO et al, 2016). Recentemente, muitas análises químicas e microbiológicas têm sido conduzidas de modo a validar a qualidade e a segurança das matérias-primas ou dos materiais sintetizados de modo a estar de acordo com a legislação vigente, sendo destacada a análise por espectroscopia na região do infravermelho e a análise térmica, associada ao emprego da termogravimetria (PAVLI et al., 2018). De modo geral, a espectroscopia de infravermelho utiliza a região do infravermelho do espectro eletromagnético (BARTH, 2007).

$\mathrm{Na}$ análise de filmes biodegradáveis, considerada uma técnica instrumental analítica nova, rápida e não-invasiva, sendo amplamente reportada na literatura (XU et al., 2015; SHARMA; SINGH, 2016; FUERTES et al., 2017; AZIZ et al., 2018; CAO et al., 2018; GHERIBI et al., 2018; MANTOVANI et al., 2018; MOHAMMADI et al., 2018; WANG et al., 2018; MATTA; TAVERA-QUIROZ; BERTOLA, 2019; TÓTH; HALÁSZ, 2019; WU et al., 2019).

Vale salientar que esse tipo de análise providencia uma ampla faixa de dados espectrais, o que torna necessária a utilização de avançadas aproximações para a análise dos dados, conforme pode ser visualizado por meio de técnicas quimiométricas, sendo destacada, no presente trabalho, a utilização do Reconhecimento de Padrões não-supervisionado composto pela Análise de Componentes Principais (PCA) e Análise de Componentes Hierárquicos (HCA).

Por outro lado, a análise térmica consiste de um conjunto de técnicas que permite medir mudanças das propriedades físicas ou químicas de um material em função da temperatura ou do tempo, o que a destaca na caracterização de filmes biodegradáveis (PETRIKOSKI, 2013).

Diante do que foi abordado, este trabalho buscou sintetizar filmes biodegradáveis a partir de amido de milho, utilizando como plastificante a glicerina e como aditivo o extrato de própolis-verde, bem como caracterizar os materiais produzidos por meio do emprego de 
espectroscopia na região do Infravermelho com transformada de Fourier (FTIR) e da análise térmica (termogravimetria), visando sua possível aplicação na produção de embalagens para a conservação de alimentos.

\section{MATERIAIS E MÉTODOS}

\subsection{Materiais utilizados}

Para a síntese dos filmes biodegradáveis, foram utilizados amido de milho (Marca MAIZENA) como agente formador; glicerina bidestilada (Marca FARMAX), como agente

plastificante e, como aditivo, o extrato de própolis-verde (Marca Natucentro). Os insumos utilizados foram adquiridos no comércio local de Bambuí, Minas Gerais. Vale reportar que se buscou utilizar materiais de baixo custo e de fácil acesso de modo a tornar a síntese economicamente viável e ambientalmente sustentável.

\subsection{Síntese dos filmes biodegradáveis}

Os filmes biodegradáveis foram obtidos através da técnica "casting” com adaptações (VEIGA-SANTOS et al., 2007; SOUZA et al., 2011). O processo de elaboração dos filmes biodegradáveis consistiu em preparar uma mistura composta por amido de milho e glicerina, nas proporções definidas na Tabela 1. Em seguida, a suspensão coloidal foi aquecida até a temperatura de $65{ }^{\circ} \mathrm{C}$ por 10 minutos, sendo o sistema mantido sob agitação manual constante até o extrato de própolis-verde ser adicionado na quantidade desejada. A solução resultante foi mantida sob aquecimento e agitação por 10 minutos. Após o término deste procedimento, as soluções filmogênicas foram vertidas em placas de suporte, sendo secas na temperatura de $25{ }^{\circ} \mathrm{C}$ durante três dias para total evaporação da água e formação dos filmes biodegradáveis. Os filmes produzidos foram armazenados em recipientes vedados da ação externa até que as análises se procedessem. Vale reportar que, para todas as formulações dos filmes, foi utilizado o mesmo volume de solução. 
Tabela 1- Matriz contendo as quantidades dos precursores empregados na síntese de filmes biodegradáveis utilizando o Planejamento Fatorial Completo

\begin{tabular}{ccccccc}
\hline Ensaio/ensaios & \multicolumn{3}{c}{ Variáveis codificadas } & \multicolumn{3}{c}{ Variáveis reais } \\
\hline $\mathbf{1}$ & - & - & - & 3 & 0,4 & 0,12 \\
$\mathbf{2}$ & - & - & + & 3 & 0,4 & 0,20 \\
$\mathbf{3}$ & - & + & - & 3 & 1,0 & 0,12 \\
$\mathbf{4}$ & - & + & + & 3 & 1,0 & 0,20 \\
$\mathbf{5}$ & + & - & - & 5 & 0,4 & 0,12 \\
$\mathbf{6}$ & + & - & + & 5 & 0,4 & 0,20 \\
$\mathbf{7}$ & + & + & - & 5 & 1,0 & 0,12 \\
$\mathbf{8}$ & + & + & + & 5 & 1,0 & 0,20 \\
$\mathbf{9 , 1 0}$ e 11 & 0 & 0 & 0 & 4 & 0,7 & 0,16 \\
\hline \multicolumn{3}{l}{ Fonte: Autores (2019). }
\end{tabular}

Com o intuito de avaliar o efeito dos parâmetros relacionados à quantidade de massa de amido de milho $\left(\mathrm{X}_{1}\right)$, de glicerina $\left(\mathrm{X}_{2}\right)$ e de extrato de própolis-verde $\left(\mathrm{X}_{3}\right)$ na preparação dos filmes biodegradáveis, os experimentos foram conduzidos empregando o Planejamento Fatorial Completo com Ponto Central.

Para as três variáveis estudadas, esse tipo de delineamento envolveu oito pontos fatoriais e três pontos centrais, contabilizando a síntese de 11 filmes biodegradáveis, conforme visualizado na equação (1).

$\mathrm{N}^{\mathrm{o}}$ de ensaios $=2 \mathrm{n}+\mathrm{n}_{\mathrm{c}}$

Em que: $\mathrm{n}$ é o número das variáveis independentes, e $\mathrm{n}_{\mathrm{c}}$ o número de pontos centrais, os quais geralmente são utilizados para a estimativa de erros quando são utilizados parâmetros estatísticos na análise de propriedades dos materiais sintetizados.

Levando em consideração resultados do grupo de pesquisa no que se refere às análises de propriedades quantitativas, cujos valores foram similares para as amostras sintetizadas com as mesmas quantidades dos precursores (ensaios nove, 10 e 11), foi empregada a amostra nove como representativa nos ensaios de caracterização conduzidos neste estudo.

Todas as sínteses foram conduzidas nas mesmas condições de temperatura e pressão no Laboratório de Biotecnologia localizado no Instituto Federal de Minas Gerais - Campus Bambuí. 


\subsection{Caracterização dos filmes biodegradáveis}

\subsubsection{Análise visual e tátil}

Após a síntese dos filmes biodegradáveis, os mesmos passaram por uma análise visual e tátil de modo a verificar o efeito das quantidades dos constituintes (amido de milho, glicerina e extrato de própolis-verde) nas suas propriedades organolépticas. Para tanto, as amostras de todos os ensaios foram submetidas à avaliação sensorial de comparação múltipla, a qual foi conduzida pelos integrantes do grupo de pesquisa.

\subsubsection{Espectroscopia na região do Infravermelho com Transformada de Fourier (FTIR)}

A espectroscopia na região do Infravermelho com Transformada de Fourier com reflectância difusa atenuada (FTIR-ATR) foi realizada para se determinar os grupos funcionais presentes nas amostras dos precursores e dos filmes biodegradáveis sintetizados. Para tanto, as amostras foram inseridas em cristal de diamante e lidas em espectrofotômetro de infravermelho (Varian, FT-IR 660, Santa Clara, Estados Unidos). As análises foram conduzidas em uma faixa espectral compreendida entre 4400 e $400 \mathrm{~cm}^{-1}$, resolução de quatro $\mathrm{cm}^{-1}$ e 64 varreduras. As análises foram conduzidas na Central de Análises e Prospecção Química (CAPQ) da Universidade Federal de Lavras (UFLA). O reconhecimento de padrões não-supervisionado através de Análise de Componentes Principais (PCA) e Análise de Componentes Hierárquicos (HCA) foram aplicados aos dados com a finalidade de verificar a similaridade entre os filmes biodegradáveis sintetizados com proporções distintas de precursores (amido de milho, glicerina e extrato de própolis-verde), bem como a influência das condições de síntese nas similaridades entre filmes e precursores.

Os dados das amostras não passaram por nenhum pré-processamento para a análise de PCA. Na HCA, foi considerado o número de componentes principais que permitiram reter a maior quantidade de informações do conjunto dos dados analisados (duas componentes principais). Utilizou-se a distância Euclideana, cujos dados foram conectados pelo vizinho mais próximo. As análises quimiométricas foram conduzidas empregando o programa Chemoface na versão 1.5 .

\subsubsection{Análise termogravimétrica}


A fim de verificar a estabilidade térmica dos filmes biodegradáveis sintetizados para futuras aplicações como embalagens para frutas, foi realizada uma análise termogravimétrica em um analisador termomecânico SHIMADZU DTG-60H. Foram utilizados aproximadamente cinco miligramas das amostras, sendo estas aquecidas a uma taxa de $10{ }^{\circ} \mathrm{C}$ $\min ^{-1}$ de $30{ }^{\circ} \mathrm{C}$ a $600{ }^{\circ} \mathrm{C}$, sob fluxo de atmosfera inerte $\left(\mathrm{N}_{2(\mathrm{~g})}\right)$. A análise foi conduzida na Central de Análise e Prospecção Química (CAPQ) da Universidade Federal de Lavras (UFLA).

\section{RESULTADOS E DISCUSSÕES}

\subsection{Análise das propriedades organolépticas (tátil e visual) dos filmes biodegradáveis}

$\mathrm{Na}$ Tabela 2, são inseridos os resultados das análises das características dos filmes biodegradáveis após os mesmos terem sido sintetizados.

Observa-se que os biofilmes que apresentam menor quantidade de glicerina são aqueles que são mais quebradiços. De acordo com abordagens descritas na literatura, o agente plastificante interage com o amido de milho por meio das ligações de hidrogênio, aumentando a flexibilidade do filme e, consequentemente, facilitando o seu manuseio. Filmes de amido são resistentes e elásticos e, na medida em que se aumenta o teor de plastificante, os materiais se tornam mais flexíveis e deformáveis (HORN, 2012).

Ainda pela análise das características dos filmes, evidencia-se que os biofilmes cinco, seis, sete e oito, os quais possuem as maiores quantidades de amido de milho, foram retirados de maneira adequada do recipiente em que foram produzidos, permitindo inferir que os mesmos apresentam maior resistência mecânica à manipulação durante a sua fabricação. A semelhança de tais resultados para os biofilmes citados está relacionada à mesma quantidade de agente formador, sendo atribuída à amilose a capacidade de formar géis. Diante de tais resultados, pode-se ainda verificar, por estes resultados, que as quantidades de glicerina e de extrato de própolis-verde não influenciaram na característica analisada.

As irregularidades observadas por meio da análise tátil dos filmes cinco e seis estão relacionadas ao difícil controle da espessura, sobretudo quando o processo de síntese acontece por meio do método casting (SOBRAL, 1999). Pode-se ainda somar esse efeito a uma quantidade inferior de glicerina, a qual por sua vez, é empregada como agente plastificante, evidenciando que os filmes sete e oito são os mais satisfatórios por apresentar uma quantidade superior desse constituinte. 
Tabela 2- Análise visual e tátil dos filmes biodegradáveis sintetizados pelo método "casting"

\begin{tabular}{|c|c|}
\hline Amostra & Características observadas \\
\hline 1 & $\begin{array}{c}\text { Cheio de rupturas. Nas extremidades apresenta boa } \\
\text { consistência, mas na região central do filme é um pouco frágil e } \\
\text { quebradiço. }\end{array}$ \\
\hline 2 & Apresenta poucas rupturas, mas muito frágil e quebradiço. \\
\hline 3 & $\begin{array}{l}\text { Desenformou por inteiro. Apresenta poucas rupturas, } \\
\text { porém é menos frágil do que os filmes } 1 \text { e } 2 \text {. }\end{array}$ \\
\hline 4 & $\begin{array}{l}\text { Não desenformou por inteiro, mas as partes que foram } \\
\text { desenformadas apresentaram irregularidades no que se refere à } \\
\text { espessura. }\end{array}$ \\
\hline 5 & $\begin{array}{l}\text { Desenformou por inteiro. Apresenta pouquíssimas } \\
\text { rupturas. Apesar de ser muito consistente, é verificado que o } \\
\text { mesmo não é totalmente homogêneo por apresentar } \\
\text { irregularidades na espessura quando se compara a região central } \\
\text { dos filmes com suas extremidades. }\end{array}$ \\
\hline 6 & $\begin{array}{l}\text { Apesar de apresentar uma única ruptura, é verificado que o } \\
\text { mesmo não é totalmente homogêneo por apresentar } \\
\text { irregularidades na espessura quando se compara a região central } \\
\text { dos filmes com suas extremidades. }\end{array}$ \\
\hline 7 & Apresenta poucas rupturas, bem consistente e homogêneo. \\
\hline 8 & Apresenta poucas rupturas, bem consistente e homogêneo. \\
\hline 9,10 e 11 & $\begin{array}{l}\text { Desenformou somente nas extremidades, sendo que mais } \\
\text { de } 90 \% \text { dos filmes obtidos são quebradiços, impossibilitando } \\
\text { descrições mais detalhadas. }\end{array}$ \\
\hline
\end{tabular}

Fonte: Autores (2019).

Vale reportar que todos os biofilmes que foram sintetizados são transparentes e não apresentaram partículas insolúveis, indicando sínteses adequadas.

\subsection{Análise de FTIR e aplicação do Reconhecimento de Padrões não-supervisionado}

Os resultados originais obtidos são apresentados na Figura 1. 


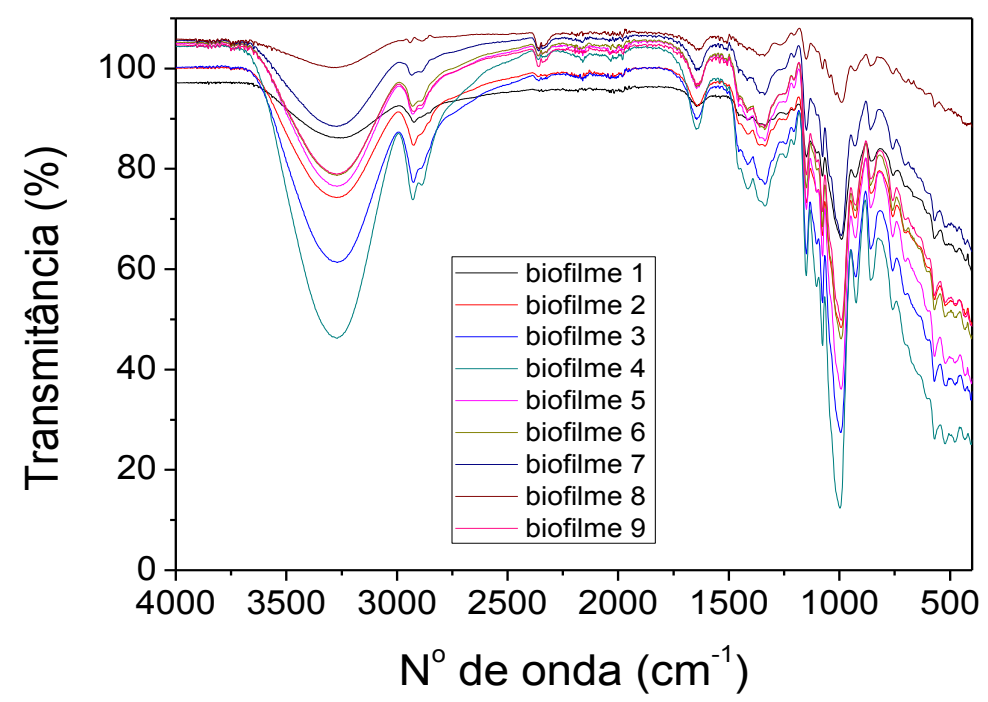

Figura 1- Espectros de absorção FTIR-ATR dos filmes biodegradáveis sintetizados Fonte: Autores (2019).

Em todos os biofilmes analisados, verificou-se um perfil de semelhança nos espectros obtidos na região do Infravermelho Médio, sendo que os mesmos se diferenciaram pela amplitude de tamanho das bandas e picos característicos de materiais constituídos pelos três componentes empregados.

Diante de tais resultados, as bandas e picos de maior intensidade que foram observados nos filmes biodegradáveis sintetizados foram então comparados com os precursores utilizados (amido de milho, glicerina e extrato de própolis-verde), sendo os dados apresentados na Tabela 3.

Conforme pode ser verificado na análise da Tabela 3, em todas as condições de síntese, os filmes biodegradáveis apresentaram bandas e/ou picos característicos dos três precursores empregados: agente formador (amido de milho), plastificante (glicerina) e aditivo (extrato de própolis-verde).

Com esses resultados, pode-se presumir que, em todas as condições de síntese, os três componentes estiveram presentes, sendo que nenhuma perda foi observada na análise espectral. Tais resultados permitem ainda inferir que a combinação dos três fatores é algo satisfatório, já que os filmes de amido de milho tendem a aumentar sua flexibilidade pela inserção da glicerina como agente plastificante. Além disso, a presença das bandas e picos referentes ao extrato de própolis-verde indica que o aditivo não foi evaporado ao longo da síntese, o que indica que todos os materiais sintetizados podem apresentar propriedades ideais para serem aplicados na embalagem de produtos alimentícios. 
Tabela 3- Bandas e picos identificados na análise FTIR observadas nos filmes biodegradáveis sintetizados e precursores

\begin{tabular}{|c|c|c|c|c|}
\hline $\begin{array}{l}\text { Bandas/picos } \\
\text { identificadas } \\
\text { (os) nos filmes } \\
\text { biodegradáveis }\end{array}$ & $\begin{array}{c}\text { Bandas/picos } \\
\text { identificadas } \\
\text { (os) no } \\
\text { precursor }\end{array}$ & Precursor & Atribuiçãa & $\begin{array}{c}\text { Grupo(s) } \\
\text { orgânico(s) }\end{array}$ \\
\hline 3272,48 & 3262,93 & \multirow{4}{*}{$\begin{array}{l}\text { Amido de } \\
\text { milho }\end{array}$} & $\mathrm{v} \mathrm{O}-\mathrm{H}$ & Álcoois \\
\hline 1337,00 & 1338,34 & & $\delta \mathrm{C}-\mathrm{H}$ & $\begin{array}{l}\text { Anéis presentes } \\
\text { no amido }\end{array}$ \\
\hline 1159,00 & 1143,57 & & v C-O & Álcoois \\
\hline 867,00 & 860,09 & & $\begin{array}{c}\delta \mathrm{COH}, \mathrm{CCH} \\
\mathrm{e} \mathrm{OCH}\end{array}$ & $\begin{array}{l}\text { Grupos laterais } \\
\text { das cadeias } \\
\text { formadores do } \\
\text { amido }\end{array}$ \\
\hline 2933,92 & 2938,50 & \multirow[t]{4}{*}{ Glicerina } & $\mathrm{v}-\mathrm{CH}_{2}$ & Metileno \\
\hline 2887,27 & 2884,08 & & $\mathrm{v}_{\mathrm{as}}-\mathrm{CH}_{2}$ & Metileno \\
\hline 1412,66 & 1415,61 & & $\mathrm{v}-\mathrm{CH}_{2}$ & Metileno \\
\hline 914,00 & 911,79 & & $\delta-\mathrm{OH}$ & Alcoóis \\
\hline 1647,39 & 1645,58 & \multirow[t]{2}{*}{$\begin{array}{l}\text { Extrato de } \\
\text { própolis- } \\
\text { verde }\end{array}$} & $\mathrm{C}=\mathrm{O}$ & $\begin{array}{c}\text { Aldeídos, cetonas } \\
\text { e ácidos } \\
\text { carboxílicos } \\
\text { presentes em } \\
\text { isoflavonas, } \\
\text { flavonóides e cera }\end{array}$ \\
\hline 1056,00 & 1043,45 & & $\begin{array}{l}\text { Dobramentos } \\
\text { C-O }\end{array}$ & $\begin{array}{c}\text { Ácidos, alcoóis, } \\
\text { ésteres }\end{array}$ \\
\hline
\end{tabular}

Fonte: Silverstein et al. (2007).

Vale salientar que devem ser avaliadas outras propriedades dos materiais com a finalidade de justificar quais as quantidades dos componentes que são mais ideais para a obtenção de filmes com propriedades e características desejáveis.

Conforme descrito anteriormente, os espectros dos filmes biodegradáveis apresentaram intensidades distintas das bandas/picos (Figura 1), sendo, portanto, necessário o emprego do reconhecimento de padrões para analisá-los minuciosamente e comparativamente, sendo que essa ferramenta também foi empregada com a finalidade de verificar quais as condições de síntese que permitiram com que os materiais sintetizados fossem mais similares aos precursores.

Os resultados são apresentados na Figura 2. 

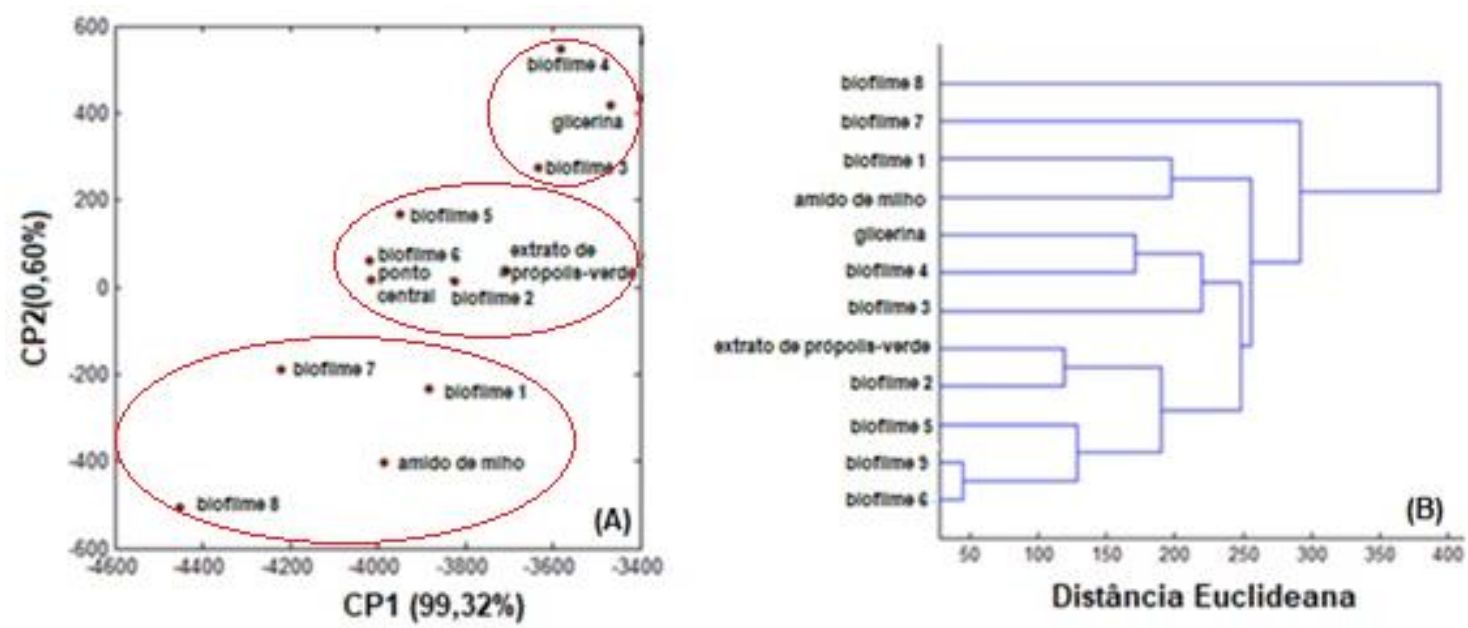

Figura 2- Análise de reconhecimento de padrões - Figura de escores da PCA (A) e dendrograma da HCA (B)

Fonte: Autores (2019).

A análise do dendrograma revelou que os filmes biodegradáveis dos ensaios seis e nove são os que apresentaram maior similaridade, sendo que o filme biodegradável cinco formou um novo grupo com as duas primeiras amostras. Estes resultados permitem evidenciar que a quantidade de própolis-verde não influenciou de maneira significativa na análise descrita, uma vez que a faixa de variação para essa variável é pequena, conforme pode ser analisado nas condições descritas na Tabela 1.

Verifica-se ainda que o filme biodegradável 2 foi o mais similar ao extrato de própolis-verde. O fenômeno está relacionado ao fato de o ensaio experimental conter uma menor quantidade de amido de milho e glicerina e uma maior quantidade do aditivo.

Por outro lado, verifica-se que o filme biodegradável quatro é o que mais se assemelha à glicerina, o que supostamente está relacionado ao fato da síntese, nessa condição, apresentar menor teor de amido de milho e maior quantidade do plastificante.

Além disso, a inserção dos filmes biodegradáveis três e quatro num mesmo grupo evidencia mais uma vez que o extrato de própolis-verde não foi um fator determinante na separação das amostras nesse tipo de análise.

O gráfico de escores mostrou a existência de três grupos de amostras, sendo que as duas primeiras componentes principais explicaram juntas 99,92\% da variabilidade dos dados, onde $99,32 \%$ foram explicados pela primeira componente principal (PC1) e 0,60\% pela segunda (PC2).

Pela análise da componente principal 1, a qual retém uma maior quantidade de informações, as amostras sintetizadas nas condições um, sete e oito foram as que apresentam menor similaridade quando comparadas com as demais condições de síntese. 
Tais resultados provavelmente estão associados ao fato de que, nessas condições de síntese, as quantidades do amido de milho (componente preponderante) estiveram nas extremidades. Como os biofilmes sete e oito pertencem ao mesmo grupo, levando em consideração a componente principal que retém uma maior quantidade de informações, podese evidenciar que o extrato de própolis-verde não influenciou na análise. $\mathrm{O}$ fenômeno se encontra associado ao fato do mesmo possuir menor quantidade em massa, ratificando as discussões descritas pela análise do dendrograma.

Verifica-se ainda que o biofilme um é o que mais se assemelha ao amido de milho. Nessa condição de síntese, os demais componentes estão no nível inferior. Como o amido de milho é o componente em maior quantidade de massa, as bandas observadas para esse biofilme em análise são as principais identificadas no agente formador.

Os espectros dos biofilmes três e quatro são os mais similares ao da glicerina, o que evidencia o fato dessas condições serem empregadas menores quantidades do agente formador e maior quantidade do agente plastificante. Como o extrato de própolis-verde é o aditivo inserido em menor proporção, verifica-se que esse parâmetro não influenciou na análise, justificando a inserção dos mesmos em um mesmo grupo.

Os demais biofilmes formam um terceiro grupo de amostras que não se destacam como os demais, já que apresentam quantidades intermediárias dos componentes analisados.

Nesse caso, pode-se reportar que as condições nas quais se empregam as quantidades mínimas e máximas dos três componentes fazem com que os resultados sejam mais distintos com relação às demais amostras nesse tipo de caracterização.

\subsection{Análise termogravimétrica}

A análise termogravimétrica foi realizada a fim de determinar o comportamento térmico dos filmes, bem como avaliar se a adição de plastificantes produz qualquer alteração no comportamento térmico de decomposição dos filmes de amido de milho. Os resultados são apresentados na Figura 3. 

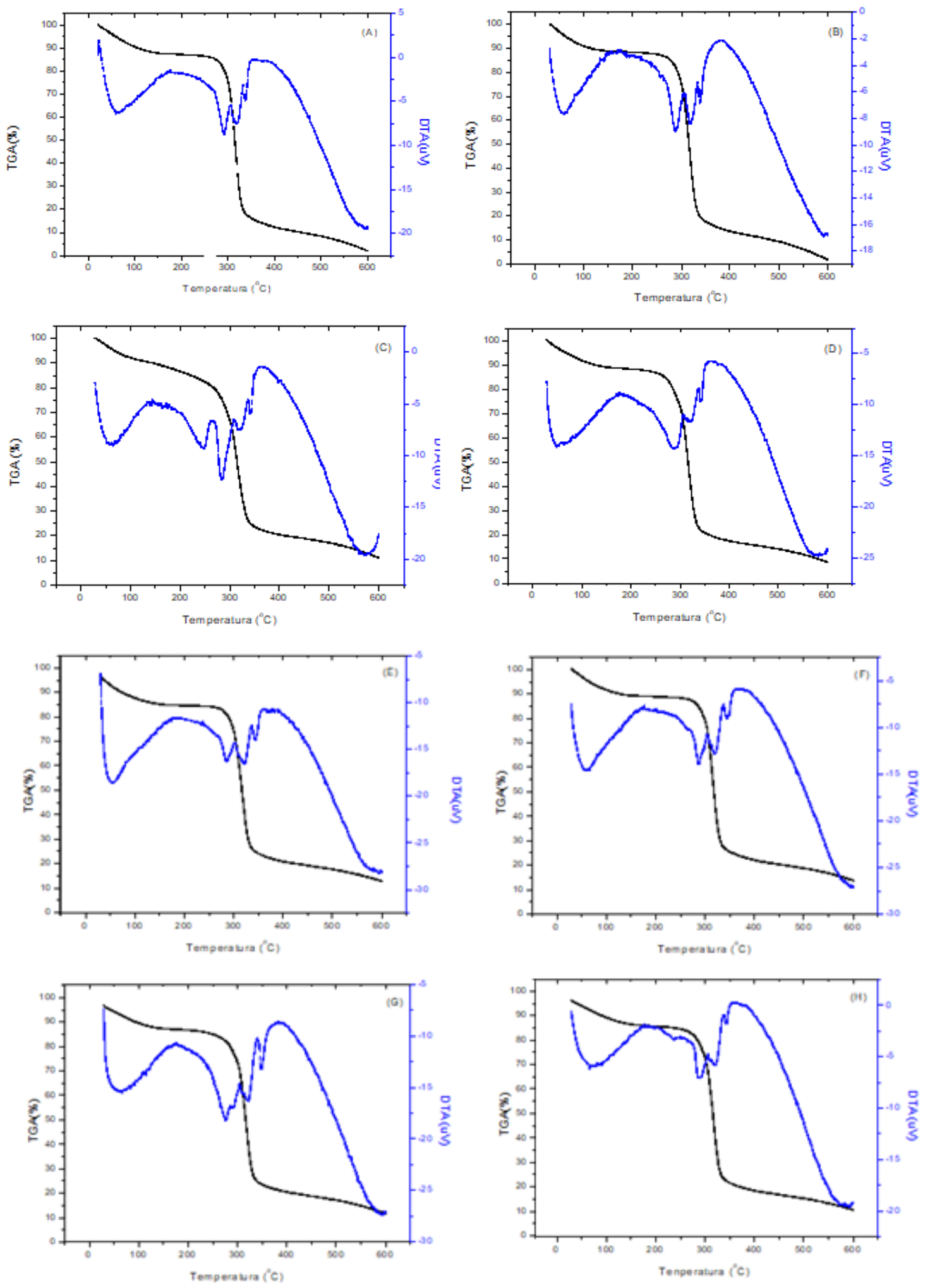

(Continua...) 


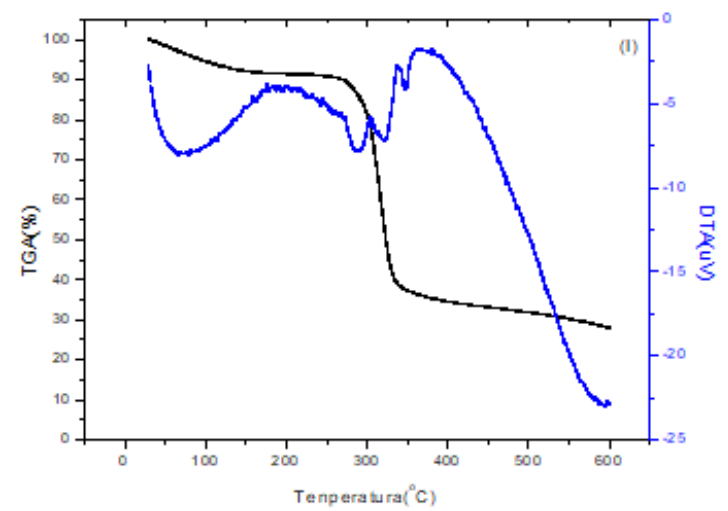

Figura 3 - Análise termogravimétrica dos filmes biodegradáveis que foram sintetizados: Filme biodegradável 1 (A); Filme biodegradável 2 (B); Filme biodegradável 3 (C); Filme biodegradável 4 (D); Filme biodegradável 5 (E); Filme biodegradável 6 (F); Filme biodegradável 7 (G); Filme biodegradável 8 (H); Filme biodegradável 9 (I)

Fonte: Autores (2019).

Observa-se um comportamento semelhante em todas as condições de síntese no que se refere a três principais eventos de perda de massa. O primeiro estágio de pequena diminuição de massa percentual, o qual ocorre em temperaturas situadas entre $30{ }^{\circ} \mathrm{C}$ e $150{ }^{\circ} \mathrm{C}$ está relacionado com a perda de água ligada e de água livre (LIU et al., 2010). De acordo com abordagens descritas na literatura, a diferença de perda de massa observada nos filmes biodegradáveis sintetizados sugere que os materiais produzidos apresentam teores diferentes de umidade (LIU et al., 2010).

Tais resultados permitem inferir que os filmes biodegradáveis produzidos apresentam potencial aplicação como coberturas e proteção de produtos alimentícios, uma vez que essa etapa está vinculada apenas ao processo de desidratação, evidenciando que o trabalho é relevante na medida em que os materiais produzidos são termicamente estáveis na temperatura ambiente, além dos mesmos serem sintetizados a partir de precursores que são de baixo custo, fácil acesso, além de serem biodegradáveis.

Entretanto, vale salientar que, para resultados mais consistentes, devem ser realizados testes que incluam a aderência na superfície do alimento que se quer proteger, além das análises das propriedades dos biofilmes que incluem solubilidade em água, permeabilidade ao vapor de água e ao oxigênio, etc.

Ainda de acordo com a análise do primeiro evento térmico, observa-se que a maioria dos filmes biodegradáveis que foram sintetizados com a mesma quantidade de amido de milho e de extrato de própolis-verde, mas que se diferenciaram pela quantidade de glicerina (filmes biodegradáveis dois e quatro; cinco e sete; seis e oito) apresentaram perdas de massa referentes ao processo de desidratação ligeiramente maiores na condição de síntese em que foi empregada uma menor quantidade do plastificante. 
De acordo com relatos descritos na literatura, tais resultados permitem inferir que os filmes biodegradáveis que possuem menor quantidade desse precursor absorvem mais umidade que os filmes que apresentam maiores quantidades de glicerol (LIU et al., 2010).

O fenômeno observado pode estar correlacionado ao fato de a glicerina como plastificante ter uma maior facilidade de se ligar à matriz de amido de milho devido à sua estrutura molecular. De um lado, tem-se o amido, um carboidrato macromolecular, um poliálcool de estrutura helicoidal que possui elevada afinidade com o plastificante. Do outro lado, o glicerol- um triálcool de baixa massa molecular. Ambas as moléculas são bastante polares e capazes de realizar interações do tipo ligações de hidrogênio entre suas hidroxilas, o que diminui os espaços entre as moléculas de amido fazendo com que as mesmas fiquem mais próximas umas das outras. Observa-se, então, a redução da espessura, diminuindo a mobilidade molecular e a possível interação com a água (SOARES et al., 2014).

Quando se avaliam os filmes biodegradáveis sintetizados com as mesmas quantidades de glicerina e extrato de própolis-verde, mas que se diferenciam pela quantidade de amido de milho verifica-se que, com exceção do par formado pelos filmes biodegradáveis quatro e oito, em todos os demais pares avaliados (filmes biodegradáveis um e cinco; dois e seis; três e sete), o aumento na quantidade de amido de milho aumenta a perda de massa associada ao processo de desidratação.

Estes resultados permitem evidenciar que quantidades mais elevadas de amido de milho tendem a absorver mais umidade, o que se mostra justificável pelo fato de uma quantidade superior desse agente formador acarretar em uma exposição superior de grupos hidroxila, os quais podem interagir por meio de ligações de hidrogênio com a água, adicionando-a facilmente à matriz polimérica (PETRIKOSKI, 2013).

A análise do termograma revela que o segundo e terceiro estágios de perda de massa estão associados com a degradação do filme, uma vez que, durante o aquecimento, as estruturas ordenadas iniciais dos filmes biodegradáveis são gradualmente destruídas. Isto pode ser possível após a quebra das ligações de hidrogênio inter e intramolecular, as quais são responsáveis pela manutenção do ordenamento da matriz polimérica nos materiais sintetizados (BARRETO, 2003).

Em relação à massa residual $(\%)$ após o aquecimento a $600{ }^{\circ} \mathrm{C}$, verificou-se que a similaridade para todas as condições de síntese que foram empregadas. Esse fenômeno pode ser atribuído ao fato dos filmes biodegradáveis serem constituídos pelos mesmos precursores, os quais diferenciaram apenas pela quantidade, conforme pode ser visualizado no planejamento quimiométrico que foi empregado. 
A análise de DTA em todas as amostras de filmes biodegradáveis revelou a existência de dois picos principais, cujas temperaturas médias dos picos foram próximas de 288 e 345 ${ }^{\circ} \mathrm{C}$, sendo que estes eventos térmicos podem ser associados aos estágios de decomposição dos filmes biodegradáveis.

Pode-se inferir que as sínteses conduzidas, neste trabalho, produziram padrões de análise térmica similares, justificável ao fato dos materiais produzidos serem compostos por amido de milho, como agente formador, glicerina, como agente plastificante e como aditivo, o extrato de própolis-verde, em que ensaios foram diferenciados pela sua quantidade.

\section{CONCLUSÃO}

No estudo que envolveu a formação de filmes biodegradáveis utilizando como agente formador o amido de milho, verificou-se que as bandas e picos observados na análise de FTIR-ATR são característicos e coerentes com os dados reportados na literatura, sendo que as intensidades de bandas/picos foram variadas conforme a interação entre os componentes.

$\mathrm{Na}$ análise de Reconhecimento de Padrões aplicada aos dados da referida técnica foi verificado que o trabalho apresenta relevância no âmbito científico e tecnológico na medida em que utilizou ferramentas quimiométricas na síntese e na análise dos materiais produzidos. Pode-se ainda inferir que a análise multivariada aplicada aos dados permitiu a facilidade de interpretação dos resultados, uma vez que uma quantidade enorme de variáveis de partida foi reduzida àquelas nas quais se concentram uma maior quantidade de informações (componentes principais).

$\mathrm{Na}$ análise termogravimétrica, verificou-se que as etapas de perdas de massa foram similares em todas as formulações, sendo que a primeira redução pode ser associada à desidratação da amostra, enquanto as demais se referem à decomposição da matéria orgânica.

Mais uma vez ressalta-se a importância deste trabalho, uma vez que as técnicas de caracterização utilizadas contam com a simplicidade no procedimento de medida e análise dos resultados.

Os resultados da análise de estabilidade térmica na temperatura ambiente e o fato dos filmes biodegradáveis sintetizados serem de baixo custo fazem com que os materiais produzidos possam ser considerados como promissores para serem adequadamente empregados na embalagem de alimentos, sendo destacados os filmes sete e oito que apresentaram características mais adequadas quando se avalia as propriedades organolépticas. 


\section{REFERÊNCIAS}

ARAÚJO, K. S. S.; et al. Physicochemical properties and antioxidant capacity of propolis of stingless bees (Meliponinae) and Apis from two regions of Tocatins, Brazil. Acta Amazonica, Manaus, v. 46, n. 1, p. 61-68, 2016.

ARAÚJO, Y. L. F. M. et al. Uso de filme biodegradável de amido à base de própolis vermelha para a conservação de folhas de alface (Lactuca sativa). Scientia Plena, Aracajú, v. 8, n. 12, p. 1-8, 2012.

AZIZ, M. A.; SALAMA, H.; SABAA, M. W. Biobased alginate/castor oil edible films for active food packaging. LWT Food Science and Technology, Amsterdam, v. 96, p. 455-460, 2018.

BARRETO, P. L. M. Propriedades físico-químicas de soluções formadoras de filmes de caseinato de sódio plastificados com sorbitol. 2003. 114 f. Tese (Doutorado em Ciências) Universidade Federal de Santa Catarina, Florianópolis, 2003.

BARTH, Andreas. Infrared spectroscopy of proteins. Biochimica et Biophysica Acta (BBA)Bionergetics. Amsterdam, v. 1767, n. 9, p. 1073-1101, 2007.

CAO, L.; LIU, W.; WANG, L. Developing a green and edible film from Cassia gum: the effects of glycerol and sorbitol. Journal of Cleaner Production, Oxford, v. 175, p. 276-282, 2018.

FUERTES, S. et al. Development and characterization of eggs yolk and egg yolk fractions edible films. Food Hydrocolloids, Oxford, v.70, p.229-239, set. 2017.

GHERIBI, R. et alDevelopment of plasticized edible films from Opontia ficus-indica mucilage: A comparative study of various polyol plasticizers. Carbohydrate Polymers, Oxford, v. 190, p. 204-211, 2018.

HORN, M. M. Blendas e filmes de quitosana/amido: estudo da influência da adição de polióis, oxidação do amido e razão amilose/amilopectina nas suas propriedades. 2012. 147 f. Tese (Doutorado em Química) - Universidade de São Paulo, São Carlos, 2012.

LIU, Y. et al.The study of electrochemically active microbial biofilms on different carbonbased anode materials in microbial fuel cells. Biosensors and Bioelectronic, Oxford, v. 25, n. 9, p. 2167-2171, 2010.

MANTOVAN, J. et al.Use of microbial levan in edible films based on cassava starch. Food Packaging and Shelf Life, Amsterdam, v.18, p. 31-36, 2018.

MATTA, E.; TAVERA-QUIROZ, M. J.; BERTOLA, N. Active edible films of methylcellulose with extracts of Green Apple (Granny Smith) skin. International Journal of Biological Macromolecules, Guildford, v. 124, p. 1292-1298, 2019.

MATTA JÚNIOR, M. D. Caracterização de biofilmes obtidos a partir de amido de ervilha (Pisum sativum) associado à goma xantana e glicerol. 2009. 107 f. Dissertação (Mestrado em Ciências) - Universidade de São Paulo, São Paulo, 2009. 
MOHAMMADI, R. et al. Physico-mechanical and structural properties of eggshell membrane gelatin-chitosan blend edible films. International Journal of Biological Macromolecules, Guildford, v. 107, p. 406-412, 2018.

PARZANESE, M. Películas y recubrimientos comestibles. Disponível em: www.alimentosaregentinos.gob.ar. Acesso em: 02 mar. 2019.

PAVLI, F. et al. Use of Fourier transform infrared spectroscopy for monitoring the shelf life of ham slices packed with probiotic supplemented edible films after treatment with high pressure processing. Food Research International, Essex, v. 106, p. 1061-1068, 2018.

PETRIKOSKI, A. P.; Elaboração de filmes biodegradáveis de fécula de mandioca e avaliação do seu uso na imobilização de caulinita intercalada com uréia. 2013. $129 \mathrm{f}$. Dissertação (Mestrado em Tecnologia de Processos Químicos e Bioquímicos) - Universidade Tecnológica Federal do Paraná, Pato Branco, 2013.

SALATINO, A. et al. Origin and chemical variation of Brazilian própolis. Evidence- Based Complementary and Alternative Medicine, Oxford, v.2, n. 1, p. 33-38, 2005.

SHARMA, L; SINGH, C. Sesame protein based edible films: Development and characterization. Food Hydrocolloids, Oxford, v. 61, p. 139-147, 2016.

SILVERSTEIN, R. M.; WEBSTER, F. X.; KIEMLE, D., J. Identificação espectrométrica de compostos orgânicos. 7. ed. Rio de Janeiro: Livros Técnicos e Científicos, 2007.

SOUZA, C. O. et al. Mango and acerola pulps as antioxidant additives in cassava starch biobased film. Journal of Agricultural and food chemistry, Washington, v. 59, n. 6, p. 22482254, 2011.

TÓTH, A.; HALÁSZ, K. Characterization of edible biocomposite films directly prepared from psyllium seed husk and husk flour. Food Packaging and Shelf Life, Amsterdam, v. 20, p. $100299,2019$.

UGALDE, M. L. et al. Active starch biopolymeric packaging film for sausages embedded with essential oil of Syzygium aromaticum. Journal of Food Science and Technology, Campinas, v. 54, n. 7, p. 2171-2175, 2017.

VEIGA-SANTOS P. et al. Mechanical properties, hydrophilicity and water activity of starchgum films: effects of additives and deacetylated xanthan gum. Food Hydrocolloids, Oxford, v. 19, p. 341-349, 2007.

WANG, X. et al. Development and characterization of agar-based edible films reinforced with nano-bacterial cellulose. International Journal of Biological Macromolecules, Guildford, v. 118, p. 722- 730, 2018.

WU, H. et al. Preparation and characterization of bioactive edible packaging films based on pomelo peel flours incorporating tea polyphenol. Food Hydrocolloids, Oxford, v. 90, p. 4149, 2019. 
XU, L. et al. Direct FTIR analysis of isolated trans fatty acids in edible oils using disposable polyethylene film. Food Chemistry, Barking, v.185, p. 503- 509, 2015.

\section{DADOS DOS AUTORES}

\section{Leonardo Silva Santos Lapa}

E-mail: leonardo_lapa@yahoo.com.br

Currículo lattes: http://lattes.cnpq.br/5642162770201188

Técnico em Meio Ambiente pelo Instituto Federal de Minas Gerais - Campus Governador Valadares. Graduando Ciências Biológicas (Licenciatura) pelo Instituto Federal de Minas Gerais - Campus Bambuí. Foi bolsista do PIBIC - Programa Institucional de Bolsas de Iniciação Científica no projeto "Síntese, Caracterização e Aplicação de Biofilmes de Baixo Custo" (2018-2019). Foi voluntário no Programa Institucional de Bolsas de Iniciação à Docência (2018-2019).

\section{Yago Ribeiro de Oliveira Silva}

E-mail: yago-180@hotmail.com

Currículo lattes: http://lattes.cnpq.br/8032676000263759

Graduando Ciências Biológicas (Licenciatura) pelo Instituto Federal de Minas Gerais Campus Bambuí. Foi voluntário do PIBIC - Programa Institucional de Bolsas de Iniciação Científica no projeto "Síntese, Caracterização e Aplicação de Biofilmes de Baixo Custo" (2018-2019). Foi bolsista no PIBID - Programa Institucional de Bolsas de Iniciação à Docência (2018-2019).

\section{Priscila Ferreira de Sales}

E-mail: priscila.sales@ cefetmg.br

Currículo lattes: http://lattes.cnpq.br/1577809067615493

Graduação em Química pela Universidade Federal de Lavras, com mestrado em doutorado em Ciências, área de concentração em Agroquímica pela mesma instituição de ensino. Foi professora substituta no IFSudeste de Minas Gerais- Campus Barbacena, no ano de 2013. Atuou como técnica de laboratório na Central de Análises e Prospecção Química na UFLA entre janeiro de 2014 e maio de 2016. Foi professora no IFMG- Campus Bambuí entre maio de 2016 e agosto de 2019. É atual professora de Química no CEFET- Unidade Nepomuceno e atua como docente no Departamento de Formação Geral. 